\title{
Elevated Carbohydrate-Deficient Transferrin (CDT) and Its Normalization on Dietary Treatment as a Useful Biochemical Test for Hereditary Fructose Intolerance and Galactosemia
}

\author{
EWA PRONICKA, MACIEJ ADAMOWICZ, AGNIESZKA KOWALIK, RAFAŁ PŁOSKI, BARBARA RADOMYSKA, \\ MAŁGORZATA ROGASZEWSKA, DARIUSZ ROKICKI, AND JOLANTA SYKUT-CEGIELSKA
}

\author{
Department of Metabolic Diseases, Endocrinology and Diabetology [E.P., A.K., M.R., D.R., J.S.-C.], Department of Laboratory \\ Diagnostics [M.A.], Children's Memorial Health Institute, Warsaw 04-730, Poland; Department of Medical Genetics [R.P.], Medical \\ University of Warsaw, Warsaw 02-007, Poland; Department of Pediatrics [B.R.], Institute of Mother and Child, Warsaw 01-211, Poland
}

\begin{abstract}
Abnormalities in protein glycosylation are reported in fructosemia (HFI) and galactosemia, although, particularly in HFI, the published data are limited to single cases. The purpose was to investigate the usefulness of the carbohydrate-deficient transferrin (CDT) profile for identification and monitoring of these disorders. First we analyzed CDT values before and shortly after the diagnosis in 10 cases of HFI and 17 cases of galactosemia. In all patients, elevated CDT levels were found that significantly $(p<0.0001)$ decreased with the therapeutic diet $(27.3 \pm 11.5 \%$ versus $9.3 \pm 5.1 \%$ for HFI and $43.8 \pm 14.1 \%$ versus $11.2 \pm 4.0 \%$ for galactosemia). To evaluate the use of CDT test in monitoring compliance, the test was performed in $25 \mathrm{HFI}$ patients on fructose- restricted diet. We found an elevated CDT level on 104 from 134 tests (mean $11.3 \pm 5.5 \%$, control $1.5 \%-6.2 \%$ ). The fructose intake was found to be $90 \pm 70$ $\mathrm{mg} / \mathrm{kg} / \mathrm{d}$, and the diet was unbalanced. A number of patients presented lower height, elevated urinary uric acid excretion, and hypercalciuria. In conclusion, abnormal percentage of CDT (\%CDT) values may allow prompt detection of HFI (or galactosemia). Persistence of some abnormalities in HFI on treatment may be caused by trace amounts of fructose ingestion and/or a deficient diet. Regular \%CDT measurements are suggested for HFI treatment monitoring. (Pediatr Res 62: 101-105, 2007)
\end{abstract}

$\mathrm{R}^{\mathrm{o}}$ outine diagnosis of fructosemia (McKusick 229600) is based on the clinical features of fructose intolerance, liver biopsy to assess aldolase B activity, and/or fructose challenge test (1). Clinical and enzymatic methods are also used to detect galactosemia (McKusick 230400) in the populations not covered by neonatal population screening (2). Delays in diagnosing both of these potentially curable inborn errors of metabolism in neonates and infants result in serious, sometimes fatal, irreversible sequelae.

Whereas a dry blood sample can be sent to a metabolic laboratory for easy detection of galactosemia, no simple metabolic test is available for the rapid identification of hereditary fructose intolerance (HFI). Diagnosis of HFI requires hospitalization in a specialized center and, in practice, often involves potentially dangerous procedures. Aldolase $\mathrm{B}(A L D O B)$ gene mutation screening represents a safe alternative, but it does not

Received November 13, 2006; accepted February 22, 2007.

Correspondence: Ewa Pronicka, M.D., Ph.D., Department of Metabolic Diseases, Endocrinology and Diabetology, Children's Memorial Health Institute, Aleja Dzieci Polskich 20, 04-730 Warsaw, Poland; e-mail: e.pronicka@czd.pl have absolute sensitivity, is relatively expensive, and, in practice, is often limited to carriers of common mutations in the $A L D O B$ gene (3-5).

In 1996, we reported that reversible hypoglycosylation of $\mathrm{N}$-glycoproteins mimicking congenital disorders of glycosylation (CDG) type I in transferrin isoforms pattern was one of the biochemical features of untreated HFI (6). The mechanism of the CDG abnormalities in HFI was subsequently examined by Jaeken et al. (7), who postulated the inhibition of phosphomannose isomerase by fructose-1-P in the liver, kidney, and intestine. Earlier, abnormal transferrin glycosylation had been found in untreated galactosemia $(8-10)$. The mechanism of abnormal glycosylation in galactose-1-phosphate uridyltransferase-deficient patients is not fully understood, but recent observation points to galactosemia as a secondary, "dual" CDG with a combined defect of assembly and processing of $N$-glycans (11).

From 1997 to 2005, assessment of CDT was extensively used in our center mainly as a part of metabolic screening for primary glycosylation disorders (12) conducted within the framework of European EUROGLYCAN and EUROGLYCANET programs. Interestingly, we observed that HFI or galactosemia were the final diagnoses in relatively many children with elevated CDT. To further increase the usefulness of the CDT determination in the diagnosis of these conditions, we also introduced a test based on CDT normalization after exclusion of fructose or galactose.

The objective of this study was to present the assessment $\mathrm{CDT}$ as an alternative method for identification of fructosemic (and galactosemic) patients. Also, we wanted to explore the potential use of CDT determination in monitoring compliance with a fructose-restricted diet in HFI.

\section{SUBJECTS AND METHODS}

The study, conducted from 1997 to 2005, comprised 31 children with fructosemia and 17 children with galactosemia. The study was approved by

Abbreviations: $A L D O B$ gene, aldolase B gene; CDG, congenital disorders of glycosylation (formerly carbohydrate-deficient glycoprotein); CDT, carbohydrate-deficient transferrin; F-1-P, fructose-1-phosphate; HFI, hereditary fructose intolerance; FFD, fructose-free diet; RDI, recommended daily intake 
the local Bioethical Committee. Informed consent was obtained from the parents and older affected children.

HFI was diagnosed based on oral fructose loading test (OFLT) and/or the presence of $A L D O B$ gene mutations on both chromosomes apart from five children who were diagnosed ex juvantibus, after marked clinical normalization on a fructose-free diet (FFD). Galactosemia was confirmed by routine quantitative determination of galactose-1-phosphate uridyltransferase activity in erythrocytes.

The first part of study comprised 10 patients with HFI and 17 patients with galactosemia who were enrolled while undergoing testing at our national pediatric metabolic center before the diagnosis was established. The age at diagnosis ranged from 2 mo to $7 \mathrm{y}$ (median $16 \mathrm{mo}$ ) for HFI and from $8 \mathrm{~d}$ to 16 mo (median $26 \mathrm{~d}$ ) for galactosemia. In these patients, the CDT was assessed before or shortly after the introduction of treatment and then followed by measurements after 2-4 wk of restriction of fructose or galactose. The influence of fructose restriction was also studied in the reference group of four children with CDG of known etiology other than HFI.

In the second part of the study examining long-term compliance with FFD and its possible influence on development, 25 children with HFI (including four HFI patients identified in the first part of study) were investigated. In all of them, the CDT test was performed in consecutive consultations. At one time point, we also assessed the composition of the diet and the children's physical development (body weight and height in relation to population averages), the presence of hepatomegaly, blood count, iron and magnesium levels, selected parameters indicative of damage to the liver (transaminases, cholesterol, prothrombin time, coagulation tests) and the kidney (calcemia and calciuria, alkaline phosphatase, blood $\mathrm{pH}$, serum and urinary uric acid levels, phosphate resorption), as well thyroid function (thyroid-stimulating hormone, free triiodothyronine, thyroxine). The age range of the study participants during the trial was 3-20 y (average $9.2 \pm 4.7 \mathrm{y}$ ), and the entire period of observation was $0.5-18$ y (average $9.4 \pm 6.0 \mathrm{y}$, median, $10 \mathrm{y}$ ).

Oral fructose tolerance test. After an overnight fast, at $0800 \mathrm{~h}$, a $20 \%$ fructose solution was administered orally at a dose of $0.5 \mathrm{~g} / \mathrm{kg}$ for $5 \mathrm{~min}$. Blood was sampled at baseline and 15, 30, 45, and 60 min. after loading. Glucose, fructose, lactate, and, in some cases, uric acid and phosphate levels were determined. The test was considered diagnostic if hypoglycemia, hypophosphatemia, an increase in fructose, lactate, and uric acid concentrations occurred. The test was interrupted by i.v. administration of glucose on appearance of hypoglycemia.

ALDOB gene mutation screening. Mutation screening was performed by direct sequencing of the coding exons and splice sites of the $A L D O B$ gene as described before (5).

Transferrin isoelectric focusing (IEF). Transferrin isoforms from ironsaturated sera (ferric citrate/sodium bicarbonate) were separated on $1 \%$ agarose gel (Iso-Gel agarose FMC) with 5\% ampholine in a pH range of 5.0-7.0 (Pharmacia Fine Chemicals) on a Multiphore 2117 apparatus (LKB) with a modified electrode lid (interelectrode distance reduced to $5.6 \mathrm{~cm}$ ). After IEF transferrin isoforms were visualized by immunofixation (polyclonal rabbit anti-human transferrin serum, DAKO) and Coomassie blue R-250 staining. The $\mathrm{OD}$ of the separated bands was determined using an Appraise densitometer (Beckman). The \%CDT was expressed as the sum of asialo-, monosialo-, and disialotransferrin fractions. The \% CDT reference values in 60 healthy children were in the range of 1.5 to 6.2 (mean 3.9, SD \pm 2.3 ).

Assessment of diet. Diet was assessed by a 3-d food records method using estimated weights. Energy, protein, fat, carbohydrate, and vitamin $\mathrm{C}$ consumption was expressed as a percentage of the Polish recommended daily intake (RDI). The fructose content of the diet was expressed in $\mathrm{mg} / \mathrm{kg} / \mathrm{d}$. The 3-d food record was kept by the parents of each of the HFI patients at home for the time closely preceding the date of the outpatient visit to our department for the clinical and biochemical examination (including CDT analysis).

\section{RESULTS}

CDT versus treatment in HFI. Before treatment, in all the children with a final diagnosis of HFI, the CDT levels were increased, whereas the introduction of a FFD led to their normalization or a significant reduction apparent after $2-4 \mathrm{wk}$ (Fig. 1). Mean CDT values were $27.3 \pm 11.5 \%$ (maximum $48.7 \%$ ) before the FFD and $9.3 \pm 5.1 \%$ after nutritional treatment. This difference was highly significant $(p<0.0001$, paired $t$ test). The FFD had no effect on CDT values in the patients with true CDG syndrome (two cases) and with galac-

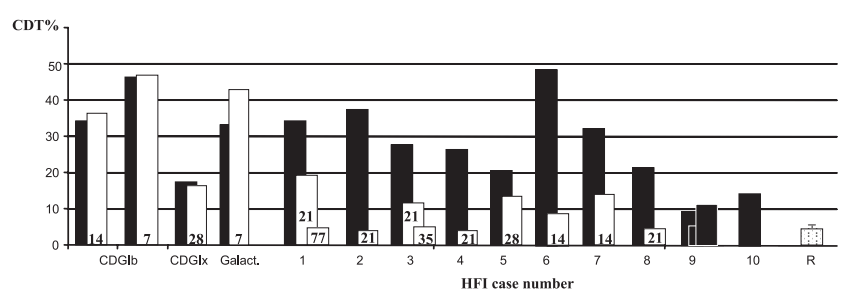

Figure 1. The \%CDT before (solid columns) and after (open columns) fructose-restricted diet in HFI patients (numbers 1-10) vs reference cases (CDG, galactosemia). Values in columns indicate the number of days on an FFD. In two patients (9 and 10), only the results before diagnosis are available. $A L D O B$ gene mutations for patients $1-3$ and 5 are shown in Table 1. Mutations in the remaining patients from Figure 1 are as follows: patient 4: A150P/A175D; patient 6: A150P/-; patients 7 and 8: no mutation in exon 5, other exons not tested; patient 9: A150P/A150P; patient 10: Y174X/Y174X. $\mathrm{R}$, reference (bar, mean; vertical line, upper range).

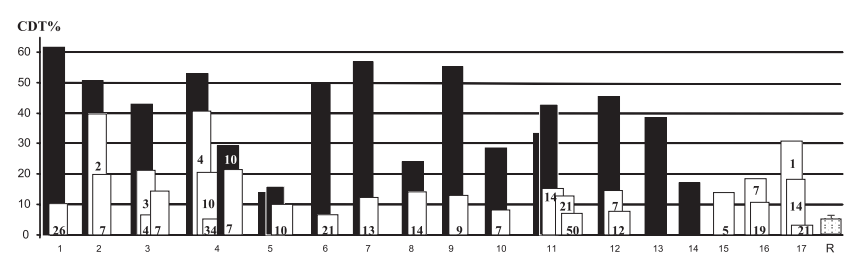

Figure 2. The \%CDT before (solid columns) and after (open columns) milk-free diet in galactosemic patients. Values in open columns indicate the number of days on a milk-free diet. For two patients (13 and 14), only the results before diagnosis were available, whereas in three $(15,16,17)$, only the results after introduction of dietary treatment were available. Patient 4 was unknowingly exposed to galactose for $10 \mathrm{~d}$ after $48 \mathrm{~d}$ of a galactose-free diet. $\mathrm{R}$, reference (bar, mean; vertical line, upper range).

tosemia (one case). Notably, in all cases of HFI, the decline in CDT levels was accompanied by marked clinical improvement.

CDT versus treatment in galactosemia. Before treatment, in all the children with galactosemia, the CDT levels were increased, whereas the introduction of a galactose-restricted diet led to their normalization or significant reduction apparent usually after only a few days (Fig. 2). The respective mean pre- and posttreatment values were $43.8 \pm 14.1 \%$ (maximum $61.6 \%)$ versus $11.2 \pm 4.0 \%(p<0.0001$, paired $t$ test). We noted that the pretreatment CDT levels were significantly higher in galactosemia compared with HFI ( $p<0.005, t$ test), although the range of values overlapped (Figs. 1 and 2).

Monitoring CDT values during treatment of fructosemia. The \%CDT values during dietary treatment of fructosemia ranged from $3 \%$ to $25.8 \%$ (average $11.3 \pm 5.5 \%$ ). Of the total 134 determinations in a group of 25 children, only 30 were within normal limits (CDT $<6.2 \%$ ). Thirty other results could have been indicative of serious glycosylation disorders as they exceeded $15.0 \%$. Table 1 shows dietary fructose ingestion by individual patients in relation to dietary characteristics and $\%$ CDT value.

Developmental and biochemical parameters in treated fructosemia. Physical development showed deficiency traits manifesting mainly as height deficiency. The average SDs for height and body weight were height, $-0.97 \pm 1.45 \mathrm{SD}$; weight, $-0.38 \pm 1.17 \mathrm{SD}$. The lowest observed normalized individual height was $-2.6 \mathrm{SD}$.

Pathologically elevated fractional uric acid excretion of $>15 \%$ was found in 16 of the 25 tested children and was 
Table 1. Long-term monitoring of \%CDT values of HFI patients on fructose-restricted diet

\begin{tabular}{|c|c|c|c|c|c|c|c|c|}
\hline $\begin{array}{c}\text { HFI } \\
\text { case } \\
\text { no. }\end{array}$ & $\begin{array}{l}\text { Year of birth/ } \\
\text { gender }\end{array}$ & $\begin{array}{c}\text { Age at } \\
\text { diagnosis }\end{array}$ & $\begin{array}{c}\text { Clinical and molecular } \\
\text { diagnosis ( } A L D O B \text { mutations) }\end{array}$ & $\begin{array}{l}\text { Observation } \\
\text { period }(\mathrm{y})\end{array}$ & $\begin{array}{l}\text { CDT measures/ } \\
\text { CDT value in } \\
\text { normal range }\end{array}$ & $\begin{array}{l}\text { CDT\%, mean } \\
\quad \text { (range) }\end{array}$ & $\begin{array}{c}\text { Fructose in } \\
\text { diet, } \mathrm{mg} / \mathrm{kg} / \mathrm{d}\end{array}$ & $\begin{array}{l}\text { Diet } \\
\text { balance } \\
\text { scale }\end{array}$ \\
\hline 1 & 1993/M & $18 \mathrm{mo}$ & OFLT A150P/A150P & 5 & $4 / 2$ & $10.2(4.7-12.4)$ & 195 & 1 \\
\hline 2 & 1984/M & $9 \mathrm{mo}$ & OFLT A150P/A175D & 9 & $5 / 1$ & $11.06(3.8-15.5)$ & 150 & 1 \\
\hline 3 & 1996/M & $20 \mathrm{mo}$ & OFLT A150P/A150P & 0.5 & $4 / 2$ & $7.5(5.7-11.7)$ & 386 & 1 \\
\hline 5 & $2000 / \mathrm{F}$ & $5 \mathrm{y}$ & OFLT A150P/- & 1 & $1 / 0$ & 8.1 & - & - \\
\hline 11 & 1977/M & $7 \mathrm{y}$ & $\begin{array}{l}\text { OFLT g922_925delgGT } \\
\text { A/c.360_363delCAAA CAAAA }\end{array}$ & 21 & $9 / 0$ & $20.2(16.9-24.5)$ & 34 & 2 \\
\hline 12 & 1991/M & $31 \mathrm{mo}$ & OFLT A150P/A150P & $61 / 2$ & $5 / 0$ & $11.2(6.1-13.5)$ & 150 & 2 \\
\hline 13 & $1985 / \mathrm{F}$ & $7 \mathrm{mo}$ & OFLT Y204X/- & 15 & $2 / 0$ & $9.1(6.9-11.3)$ & 80 & 1 \\
\hline 14 & $1986 / \mathrm{F}$ & $9 \mathrm{mo}$ & OFLT A150P/A150P & 17 & $9 / 0$ & $12.5(8.3-19.9)$ & 48 & 3 \\
\hline 15 & 1987/M & $11 \mathrm{mo}$ & OFLT A150P/A150P & 16 & $5 / 0$ & $10.9(7.1-13.6)$ & 76 & - \\
\hline 16 & $1987 / \mathrm{F}$ & $7 \mathrm{mo}$ & OFLT A150P/A150P & 5 & $2 / 0$ & $5.7(5.3-6.2)$ & 164 & 3 \\
\hline 17 & 1987/M & $18 \mathrm{mo}$ & OFLT A150P/Y174X & $41 / 2$ & $3 / 0$ & $10.0(6.9-12.8)$ & 96 & 3 \\
\hline 18 & 1987/M & $40 \mathrm{mo}$ & OFLT A150P/A150P & 13 & $2 / 1$ & $13.1(5.3-20.9)$ & 106 & 3 \\
\hline 19 & $1987 / \mathrm{F}$ & $11 \mathrm{mo}$ & OFLT A150P/- & 16 & $2 / 0$ & $16.7(12.4-21.1)$ & - & - \\
\hline 20 & $1988 / \mathrm{F}$ & $9 \mathrm{mo}$ & OFLT A150P/g.922_925 delgGTA & 15 & $4 / 2$ & $9.9(5.9-14.2)$ & 30 & 3 \\
\hline 21 & $1988 / \mathrm{F}$ & $9 \mathrm{mo}$ & OFLT A150P/c.313_314 ins12nt & 11 & $2 / 0$ & $7.0(6.9-7.1)$ & 99 & 2 \\
\hline 22 & 1989/M & $24 \mathrm{mo}$ & OFLT A150P/A150P & 13 & $7 / 3$ & $11.6(4.3-21.3)$ & 52 & 2 \\
\hline 23 & 1989/F & $5 \mathrm{mo}$ & OFLT A150P/A150P & 11 & $1 / 0$ & 8.1 & 346 & - \\
\hline 24 & 1991/M & $5 \mathrm{mo}$ & OFLT A150P/A150P & 7 & $3 / 2$ & $6.2(3.3-8.3)$ & 36 & 1 \\
\hline 25 & 1991/M & $36 \mathrm{mo}$ & OFLT A150P/A150P & 9 & $5 / 1$ & $11.3(5.4-16.0)$ & 138 & 3 \\
\hline 26 & $1992 / \mathrm{F}$ & $7 \mathrm{mo}$ & OFLT A150P/c. 250 delC & 17 & $9 / 0$ & $12.8(10.9-25.8)$ & 112 & 2 \\
\hline 27 & $1992 / \mathrm{F}$ & $4 y$ & $\begin{array}{l}\text { Typical clinical picture and } \\
\text { courseMut }-/-\end{array}$ & 10 & $9 / 5$ & $7.7(5.7-15.2)$ & 62 & 3 \\
\hline 28 & 1993/M & $14 \mathrm{mo}$ & OFLT A150P/c.250 delC & 11 & $5 / 1$ & $11.02(6.2-13.5)$ & 179 & 2 \\
\hline 29 & $1993 / \mathrm{F}$ & $24 \mathrm{mo}$ & OFLT A175D/A175D & 9 & $12 / 2$ & $12.5(3.5-20.6)$ & 112 & 3 \\
\hline 30 & 1995/M & $4 y$ & OFLT A150P/A150P & 6 & $6 / 2$ & $10.8(8.4-15.6)$ & 156 & - \\
\hline 31 & 2002/M & At birth* & OFLT A150P/C 250delC & 3 & $4 / 0$ & $17.6(11.6-23.4)$ & - & - \\
\hline
\end{tabular}

Diet balance scale: 1, balanced; 2, low carbohydrate intake; 3, low calorie and carbohydrate intake. - , not assessed.

* Older sibling affected (patient 26).

usually accompanied by a decreased serum uric acid concentration to $<5 \mathrm{mg} \%$ (in 14 children). Mean values in the entire group were $7 \%-33 \%$ (average $16.1 \pm 6.2 \%$, normal $<15 \%$ ) for fractional uric acid excretion and $1.0-5.9 \mathrm{mg} \%$ (average $3.3 \pm 1.1 \mathrm{mg} \%$ ) for serum uric acid concentration.

A tendency toward hypercalciuria was also observed. Daily urinary calcium excretion ranged from 0.03 to $0.22 \mathrm{mmol} /$ $\mathrm{kg} / 24 \mathrm{~h}$ (average $0.1 \pm 0.05 \mathrm{mmol} / \mathrm{kg} / 24 \mathrm{~h}$, normal value $<0.12 \mathrm{mmol} / \mathrm{kg} / 24 \mathrm{~h}$ ). In six cases, calcium excretion exceeded $0.12 \mathrm{mg} / \mathrm{kg} / 24 \mathrm{~h}$. Increased phosphate excretion was also observed in six cases.

The liver was slightly enlarged in six children. No distinct abnormalities in blood count, blood coagulation parameters, aminotransferases, protein, cholesterol, iron, or magnesium levels were found. No abnormal thyroid test results were observed in the treated children. In at least three patients, abnormal results of these tests had been the basis for introducing treatment with thyroid medications before the diagnosis of HFI had been made (Rogaszewska et al., 6th AsianEuropean Annual Workshop on Inborn Errors of Metabolism (AEWIEM), October 26-30, 2000, Chunchon, Korea).

Analysis of fructose-restricted diet. Analysis of food diaries showed that many of the children consumed excessive amounts of fructose, also as a component of medications. The dietary fructose level averaged $2.6 \pm 1.4 \mathrm{~g} / \mathrm{d}$ and did not exceed the recommended $2 \mathrm{~g} / \mathrm{d}$ in only eight cases. When expressed per unit of body weight, on the basis of 48 food diaries of 25 HFI children (1-3× for each child), fructose consumption ranged between 20 and $390 \mathrm{mg} / \mathrm{kg} / \mathrm{d}$ and averaged $90 \pm 70 \mathrm{mg} / \mathrm{kg} / \mathrm{d}$.

Overall, the patients' diets were found to be high in protein $(137 \pm 46 \%)$ and fat $(122 \pm 45 \%)$ and low in carbohydrate $(67 \pm 21 \%)$ in comparison with RDI. The energy supply $(52 \%-123 \%$, average $93 \pm 26 \%$ of RDI) and carbohydrate was clearly insufficient in 12 of 27 assessed HFI patients. An inadequate dietary vitamin $\mathrm{C}$ supply was also found (8\%$160 \%$ of daily values, median $50 \%$ of RDI).

No clear statistical correlation was found among the examined parameters, including abnormal biochemistry results, serum CDT\% values, and fructose consumption (based on declared 3-d food diaries). The only tendency observed was that the children with growth deficiency were more likely to have abnormal glycosylated transferrin values and dietary energy deficiency.

\section{DISCUSSION}

The molecular data on the disease frequency in various populations indicate that HFI is a relatively common disorder (approximately 1:20,000 births), yet all authors agree that it is significantly underdiagnosed. The need for rapid diagnosis of HFI is becoming increasingly urgent in light of the growing use of processed foods containing artificial sweeteners (sorbitol, fructose, high fructose corn syrup solids), making increas- 
ing numbers of unrecognized patients become symptomatic $(12,13)$.

In our study, determining serum CDT was found to be an effective method of identifying HFI, and galactosemia. These results are of particular importance in relation to HFI, for which a simple metabolic test is not available. The diagnosis of HFI was made with a considerable delay from the onset of symptoms, on average, at the age of 23 mo. Similarly, as described in the literature, many of the HFI patients had been hospitalized numerous times and subjected to diagnostic biopsies of the liver, muscles, and kidneys as well as to enzymatic and molecular testing for various metabolic diseases (12-18).

Delays in diagnosing HFI are frequent not only in our experience. The time to diagnosing HFI at pediatric metabolic centers can considerably exceed the "exemplary" time of 1 mo given in the recent analysis from Toronto (19). The neurologic symptoms (20), hypoglycemia as well as recurrent vomiting, and isolated hypertransaminasemia (21) occur also in congenital glycosylation disorder type Ib $(22,23)$ and can steer metabolic diagnostics in the wrong direction.

In our study, CDT was surprisingly elevated also in the children with HFI on long-term dietary treatment. Normal CDT values were found in only 30 of a total 134 determinations; moreover, these values improved in individual cases through regular consultations with an experienced dietitian. A side effect of long-term strict avoidance of fructose was a clearly unbalanced diet containing an excess protein and fat, a shortage of carbohydrates, and often a deficient energy supply. Similar qualitative and quantitative changes in diet composition were reported by Mock et al. (24) in their two HFI cases.

In our opinion, the CDT level during treatment of HFI objectively reflects fructose intake and is superior to dietary analysis based on food diaries. Similarly, in galactosemia, it was shown that abnormal glycoforms persist on a galactoserestricted diet, and it was suggested that CDT detection might be a useful predictor of treatment outcome in this disease (10).

It remains to be shown whether less than satisfactory compliance with an FFD has long-term adverse consequences. In our study, the average height of all patients with fructosemia on an FFD was less in comparison with the healthy population. It is difficult to determine whether the height deficit of HFI patients is due to the presence of trace amounts of fructose in the diet or to qualitative and quantitative dietary deficiencies that are a side effect of the elimination diet.

Other authors have also made this observation. Mock et al. (24) suggested that growth deficiency in fructosemia is caused by inadequate fructose restriction. The diets of two children with an early diagnosis of HFI who exhibited growth deficiency contained $110-450 \mathrm{mg} / \mathrm{kg}$ of fructose per day without causing any symptoms of intolerance in the form of unusual abdominal pain, vomiting, symptomatic hypoglycemia, or hepatopathy. Reducing fructose intake to $20-40 \mathrm{mg} / \mathrm{kg} / \mathrm{d}$ (24) led to catch-up growth (from $-2.40 \mathrm{SD}$ to $+0.3 \mathrm{SD}$ and from the 25th to the 97th percentile). A special dietary study with stringent and relaxed short-term fructose restriction revealed a correlation between the serum fructose level and uric acid and magnesium levels (24).
Recent studies have reported that the coexistence of celiac disease can also lead to growth deficit in HFI (25). We did not investigate this possibility in our study. Regardless of the causes of growth deficiency in fructosemia, our results point to the necessity of each HFI patient being under the regular care of an experienced metabolic dietitian.

In our study, we also found abnormalities in uric acid metabolism in the HFI-affected children long after the diagnosis was established. Increased renal loss of uric acid associated with lower serum uric acid levels indicated impaired tubular resorption. The influence of fructose, more specifically fructose-1-phosphate (F-1-P), on uric acid metabolism is well known $(12,13,24)$ and also applies to healthy individuals. In a short-term experiment, the serum level of uric acid increased after fructose loading, this effect being more distinct in persons affected with fructosemia. It is known that F-1-P depletes the adenosine triphosphate pool and stimulates purine metabolism. Hyperuricosuria in HFI is caused by two mechanisms: the overproduction of uric acid (mentioned above) and deficient reuptake as the result of Fanconi-DeToni-Debre type tubulopathy. Interestingly, in our study, only the effect of F-1-P on the renal stage of the uric acid pathway became apparent in children consuming trace amounts of fructose. The serum uric acid level was not elevated, but often was at or below the lower limit of normal (Table 1). Reports about the occurrence of hypouricemia in HFI are sporadic (15). The importance of this observation requires a study with a larger number of participants.

In our study, by assaying serum CDT as a part of early symptomatic screening for metabolic disorders, we made an initial diagnosis of 17 cases of galactosemia in neonates and young infants in addition to identifying cases of fructosemia. The frequency of galactosemia is estimated to be $1: 23,000$ to $1: 44,000$ births (26). According to a rough estimate, the number of cases detected in this study amounted to $28 \%$ of all unrelated patients with galactosemia diagnosed in the same period in Poland. It should be stressed that in contrast with enzymatic assays, blood transfusions do not affect CDT values in untreated galactosemia. A limitation of this test is that the results can be ambiguous before $2 \mathrm{wk}$ of age and are abnormal (and diagnostic) only when milk is included in the diet.

In summary, our results show that elevated CDT and its normalization on dietary treatment is a useful biochemical test for HFI and galactosemia. Also, the CDT assay may be used to monitor compliance with an FFD, which appears to be a significant unrecognized problem in HFI patients.

\section{REFERENCES}

1. Steinmann B, Gitzelmann G, Van ben Berghe G 2001 Disorders of fructose metabolism. In: Scriver CR, Beaudet AL, Sly WS, Valle D (eds), Childs B, Kinzler KW, Vogelstein B (assoc eds): The Metabolic and Molecular Bases of Inherited Disease. McGraw-Hill, New York, pp 1489-1520

2. Holton JB, Walter JH, Tyfield LA 2001 Galactosemia. In: Scriver CR, Beaudet AL, Sly WS, Valle D (eds), Childs B, Kinzler KW, Vogelstein B (assoc eds): The Metabolic and Molecular Bases of Inherited Disease. McGraw-Hill, New York, pp 1553-1583

3. James CL, Rellos P, Ali M, Heeley AF, Cox TM 1996 Neonatal screening for hereditary fructose intolerance: frequency of the most common mutant aldolase $\mathrm{B}$ allele (A149P) in the British population. J Med Genet 33:837-841

4. Santer R, Rischewski J, von Weihe M, Niedorhaus M, Scheppenheim S, Baerlocher K, Kohlschutter A, Muntau A, Posselt H-G, Steinmann B, Schneppenheim R 2005 
The spectrum of aldolase B (ALDOB) mutations and the prevalence of hereditary fructose intolerance in Central Europe. Hum Mutat 25:594

5. Gruchota J, Pronicka E, Korniszewski L, Stolarski B, Pollak A, Rogaszewska M, Płoski R 2006 Aldolase B mutations and prevalence of hereditary fructose intolerance in a Polish population. Mol Genet Metab 87:376-378

6. Adamowicz M, Pronicka E 1996 Carbohydrate deficient syndrome-like transferrin isoelectric focusing pattern in untreated fructosaemia. Eur J Pediatr 155:347-348

7. Jaeken J, Pirard M, Adamowicz M, Pronicka E, Van Schaftinger E 1996 Inhibition of phosphomannose isomerase by fructose 1-phosphate. Pediatr Res 40:764-766

8. Jaeken J, Matthijs G, Carchon H, Van Schaftingen E 2001 Defects of N-glycan synthesis. In: Scriver CR, Beaudet AL, Sly WS, Valle D (eds), Childs B, Kinzler KW, Vogelstein B (assoc eds): The Metabolic and Molecular Bases of Inherited Disease. McGraw-Hill, New York, pp 1601-1622

9. Jaeken J, Kint J, Spaapen L 1992 Serum lysosomal enzyme abnormalities in galactosemia. Lancet 340:1472-1473

10. Charlwood J, Clayton P, Keir G, Mian N, Winchester B 1998 Defective galactosylation of serum transferrin in galactosemia. Glycobiology 8:351-357

11. Sturiale L, Barone R, Fiumara A, Perez M, Zaffanello M, Sorg G, Pavone L, Tortorelli S, O'Brien JF, Jaeken J, Garozzo D 2005 Hypoglycosylation with increased fucosylation and branching of serum transferrin in untreated galactosemia. Glycobiology 15:1268-1276

12. Wong D 2005 IEM digest. Hereditary fructose intolerance. Mol Genet Metab 85:165-167

13. Ali M, Rellos P, Cox TM 1998 Hereditary fructose intolerance. J Med Genet 35:353-365

14. Jamar S, Evenepoel P, Kuypers D, Maes B Vanrenterghem Y 2003 A young patient with unexplained acute hepatorenal dysfunction. Nephrol Dial Transplant 18:1220-1222

15. Stormon MO, Cutz E, Furuya K, Bedford M, Yerkes L, Tolan DR, Feigenbaum A 2004 A six-month-old infant with liver steatosis. J Paediatr 144:258-263
16. Briones P, Vilaseca MA, Garcia-Silva MT, Pineda M, Colomer J, Ferrer I, Artigas J, Jaeken J, Chabas A 2001 Congenital disorders of glycosylation (CDG) may be underdiagnosed when mimicking mitochondrial disease. Eur J Paediatr Neurol 5:127-131

17. Jaeken J, Carchon H 2001 Congenital disorders of glycosylation: the rapidly growing tip of the iceberg. Curr Opin Neurol 14:811-815

18. Leonard J, Grunewald S, Clayton P 2001 Diversity of congenital disorders of glycosylation. Lancet 357:1382-1383

19. Glass HC, Feigenbaum A, Clarke JT 2006 A study on the nature of genetic metabolic practice at a major paediatric referral centre. J Inherit Metab Dis 29:175-178

20. Labrune P, Chatelon S, Huguet P, Odievre M 1990 Unusual cerebral manifestations in hereditary fructose intolerance. Arch Neurol 47:1243-1244

21. Iorio R, Sepe A, Giannattasio A, Cirillo F, Vegnente A 2005 Hypertransaminasemia in childhood as a marker of genetic liver disease. J Gastroenterol 40:820-826

22. Babovic-Vuksanovic D, Patterson MC, Schwenk WF, O'Brien JF, Vockley J, Freeze HH, Mehta DP, Michels VV 1999 Severe hypoglycemia as a presenting symptom of carbohydrate-deficient glycoprotein syndrome. J Pediatr 135:775-781

23. de Lonlay P, Cuer M, Vuillaumier-Barrot S, Beaune G, Castelnau P, Kretz M, Durand G, Saudubray J-M, Seta N 1999 Hyperinsulinemic hypoglycemia as a presenting sign in phosphomannose isomerase-deficient glycoprotein syndrome treatable with mannose. J Pediatr 135:379-383

24. Mock DM, Perman JA, Thaler M, Morris RC 1983 Chronic fructose intoxication after infancy in children with hereditary fructose intolerance. A cause of growth retardation. N Engl J Med 309:764-770

25. Ciacci C, Gennarelli D, Esposito G, Tortora R, Salvatore F, Sacchetti L 2006 Hereditary fructose intolerance and celiac disease. Clin Gastroenterol Hepatol 4:635-638

26. Bosch AM 2006 Classical galactosemia revisited. J Inherit Metab Dis 29:516-525 